\title{
ESTRATÉGIA DE APRIMORAMENTO DO ENSINO DO EXAME FİSICO EM ENFERMAGEM
}

Ana Luisa Brandão de Carvalho Lira', Maria Isabel da Conceição Dias Fernandes², Isadora Andriola Costa ${ }^{3}$, Rayanne Suely da Costa Silva ${ }^{4}$

Objetivou-se neste artigo relatar a experiência da construção e execução da ação de extensão sobre curso de exame físico. Estudo descritivo, do tipo relato de experiência, acerca da ação de extensão, destinada aos discentes do 4 o período do curso de graduação em enfermagem de uma universidade federal do nordeste. A ação ocorreu em três momentos distintos, a saber: apresentação de vídeo temático, demonstração prática do exame físico e jogo educativo. Concluiu-se que os professores devem utilizar técnicas de ensino que possibilitem interações mais dinâmicas com os discentes em detrimento das tradicionais metodologias conservadoras que são, em essência, fragmentadas e reducionistas.

Descritores: Enfermagem, Ensino, Exame Físico.

\section{SCHOOL IMPROVEMENT STRATEGY OF PHYSICAL EXAMINATION IN NURSING}

The objective of this article is to report the experience of building and execution the extension course of action on physical examination. A descriptive Study of type experience report, about the extension action, aimed at students of the 4th period of the degree course in nursing at a federal University of the Northeast. The action occurred in three different times, namely: thematic video presentation, practical demonstration of physical examination and educational game. It was concluded that the teachers should use teaching techniques that allow more dynamic interactions with learners at the expense of the traditional conservative methodologies which are, in essence, fragmented and reductionist.

Descriptors: Nursing, Teaching, Physical Examination.

\section{ESTRATEGIA DE MEJORA DE LA ESCUELA DE EXAMEN FÍSICO DE ENFERMERÍA}

El objetivo de este artículo is informe de la experiencia de construcción y ejecución del curso de extensión de la acción en el examen físico. Estudio descriptivo de tipo experiencia informe, acerca de la acción de extensión, dirigida a estudiantes del 4 o periodo de la licenciatura en enfermería de la Universidad federal del noreste. La acción se produjo en tres ocasiones diferentes, a saber: video presentación temática, demostración práctica del examen físico y juego educativo. Se concluyó que los maestros deben utilizar técnicas de enseñanza que permiten interacciones más dinámicas con los educandos a expensas de las metodologías tradicionales y conservadores que son, en esencia, fragmentados y reduccionistas.

Descriptores: Enfermería, Enseñanza, Examen Físico.

'Enfermeira. Doutora. Docente da Universidade Federal do Rio Grande do Norte- UFRN. E-mail: analuisa_brandao@yahoo.com.br.

${ }^{2}$ Enfermeira. Mestre em Enfermagem.

${ }^{3}$ Enfermeira. Graduada pela UFRN.

${ }^{4}$ Enfermeira. Graduada pela UFRN 


\section{INTRODUÇÃO}

A capacidade de avaliar os pacientes é uma das habilidades mais importantes da enfermagem. Em todos os ambientes em que as enfermeiras interagem com pacientes e lhes prestam cuidados, a obtenção de uma história de saúde completa e a utilização das habilidades de avaliação apropriadas são essenciais para a identificação dos seus problemas físicos e psicológicos ${ }^{(1)}$.

Após a aquisição da história de saúde do paciente, geralmente, realiza-se o exame físico, que se trata de uma avaliação organizada e sistemática das regiões e sistemas específicos do corpo humano, cujo objetivo é obter dados apropriados no menor intervalo de tempo. Para isso, são utilizados instrumentos básicos, como a visão, audição, tato e olfato. Tais instrumentos possibilitam a execução dos métodos propedêuticos

fundamentais do exame físico, a saber: inspeção, palpação, percussão e ausculta, complementadas por equipamentos especiais que permitem melhor definição de detalhes ${ }^{(1-2)}$.

A realização do exame físico de enfermagem é uma fase essencial de uma assistência sistematizada que deve ser executada de forma criteriosa pelos enfermeiros, visando uma atuação científica e com competência embasada por conhecimentos próprios

(3). O exame físico faz parte de uma etapa primordial do processo de enfermagem (PE), o histórico, sendo a partir dele, conjuntamente com a anamnese, que o enfermeiro traça os diagnósticos de enfermagem, e assim, planeja a sua assistência voltada para as reais necessidades do paciente ${ }^{(4)}$.

O PE é definido como um instrumento metodológico que possibilita ao enfermeiro identificar, compreender, descrever, explicar e predizer os problemas de saúde do cliente, assim como, determinar quais aspectos das respostas do paciente exige intervenção profissional para alcançar resultados esperados ${ }^{(5)}$

Destarte, para conhecer as condições deste cliente, detectar suas necessidades e prescrever a assistência de enfermagem é necessário que o enfermeiro examine o enfermo de maneira completa, utilizando seus conhecimentos de anatomia, fisiologia, patologia clínica, psicologia, exames complementares e semiologia e semiotécnica da enfermagem, com a finalidade de estabelecer intervenções coerentes com as necessidades do cliente ${ }^{(4)}$.

Assim, é imprescindivel que na graduação o estudante de enfermagem torne-se capaz de utilizar o processo de enfermagem, e consequentemente o exame físico, na avaliação de saúde individual do adulto, habilidade introduzida pela disciplina de semiologia e semiotécnica da enfermagem. Esta disciplina tem como proposta o ensino-aprendizado dos conceitos e técnicas iniciais necessárias à assistência de enfermagem. Além disso, é durante esta matéria que os conteúdos do exame físico são trabalhados, sendo complementado por outras disciplinas posteriormente ${ }^{(4,6)}$.

Em um estudo realizado sobre exame físico em uma escola de graduação em enfermagem, verificou-se que $51,3 \%$ dos docentes sentiam-se em parte aptos a ensinar exame físico aos discentes, $46,1 \%$ sentiamse aptos, e 2,6\% não se sentiam aptos, evidenciando que $\circ$ ensino do exame físico na graduação não foi satisfatório para grande parte dos docentes no que tange ao respaldo para ensinar sobre 0 assunto (4).

Entretanto, segundo resoluçãodoCOFEN358/2009, a obtenção de dados sobre a pessoa, familia e comunidade acerca das suas respostas do processo de saúde/ doença, em um determinado momento, é uma das funções e responsabilidades do enfermeiro (7). É indispensável, pois, que esse assunto seja aprimorado na graduação no transcorrer das disciplinas, durante a graduação, para que o aluno, futuro profissional, possa exercer sua prática de modo a fornecer um cuidado com mais segurança, autonomia e autoridade ${ }^{(4)}$.

Frente a esses desafios, docentes e monitores, da disciplina de semiologia e semiotécnica da enfermagem de uma universidade federal do nordeste, desenvolveram uma ação de extensão com o intuito de despertar o interesse e a prática das habilidades propedêuticas nos discentes para a realização do exame físico geral em pacientes. Deste modo, pretendeu-se colaborar para uma prática segura e embasada cientificamente, não só durante o processo de formação acadêmica, mas também visando o exercício profissional futuro. Dessa forma, o objetivo do presente trabalho é relatar a experiência da construção e execução da ação de extensão sobre curso de exame físico. 


\section{MATERIAIS E MÉTODOS}

Estudo descritivo, do tipo relato de experiência, acerca da ação de extensão "III Curso sobre exame físico do adulto: aprimorando as habilidades propedêuticas na enfermagem", destinada aos discentes do 4 o período do curso de graduação em enfermagem de uma universidade federal do nordeste, os quais cursavam a disciplina semiologia e semiotécnica da enfermagem.

A ação desenvolvida conjuntamente pela professora orientadora e as monitoras da referida disciplina, ocorreu durante três dias consecutivos, nos dois semestres de 2011 e no primeiro semestre de 2012, com uma carga horária total de 20 horas, as quais foram distribuidas em três momentos distintos, a saber: apresentação de vídeo temático, demonstração prática do exame físico e jogo educativo.

As técnicas de ensino utilizadas no curso, como o vídeo, a demonstração e o jogo educativo foram empregadas a fim de propor aos alunos uma forma interativa de ensino/ aprendizagem, diferente do convencional, e que os levassem a ter uma aprendizagem significativa.

\section{RESULTADOS E} DISCUSSÃO

O processo de aprendizado pode ser descrito em quatro etapas básicas, cada uma com características próprias imprescindiveis à aquisição de competências pelos alunos, a saber: o sentir, denominado como experiência concreta; o observar, no qual há a observação reflexiva; o pensar, que refere-se a conceitualização abstrata; e o fazer, na qual há a experimentação ativa ${ }^{(8)}$.

Os professores, juntamente com os estudantes, assumem papéis ativos na construção do conhecimento, e devem guiar sua atuação no sentido de trilhar percursos e itinerários a serem percorridos pelos alunos de modo a promover uma facilitação no aprendizado. Para isso, devem utilizar recursos que sejam capazes de viabilizar uma aprendizagem significativa, contribuindo para o desenvolvimento de competências e habilidades. A aprendizagem significativa ocorre quando novas informações somam-se a conceitos relevantes preexistentes na estrutura cognitiva de quem aprende. E para que esta aconteça o conhecimento precisa ser significativo ${ }^{(9)}$.
Portanto, a fim de estimular o raciocínio e promover uma aprendizagem significativa, os docentes devem desenvolver atividades que envolvam exposição, tutoria, simulação e questionamentos ${ }^{(9)}$. Nesse sentido, durante a realização do referido curso foram utilizados tais recursos, os quais serviram de apoio aos docentes e monitores na condução do processo de ensino-aprendizagem.

Foi apresentado, em um primeiro momento, um vídeo, desenvolvido por enfermeiras e pós-graduandos do Departamento de Enfermagem da Universidade Federal de São Paulo ${ }^{(10)}$, o qual permitiu aos discentes visualizar a realização do exame físico completo. O vídeo possui duração de 1 hora e 30 minutos e aborda o exame físico céfalo-caudal, enfocando a ectoscopia e o exame dos segmentos. Além disso, são discutidos os métodos propedêuticos e a importância destes para o aperfeiçoamento do raciocínio clínico e julgamento diagnóstico do enfermeiro.

As informações apresentadas por meio do vídeo permitiram não apenas a integração de todo o conteúdo sobre exame físico ministrado ao longo da disciplina, como também, a visualização da prática do exame físico de maneira holística. $\mathrm{O}$ uso da multimídia em sala de aula viabiliza aos estudantes a aprendizagem dos conteúdos de uma forma mais rápida, mais fácil e completa (11).

O segundo momento do curso foi marcado, inicialmente, pela demonstração prática do exame físico completo pelas monitoras e docente e, posteriormente, ocorreu o treinamento dos discentes em duplas. Nesse momento, desenvolveram-se atividades de tutoria e simulação, nas quais o professor e monitores, além de darem continuidade à exposição, interagiram com os alunos e puderam corrigir erros e falhas, como também promoveram a prática de um caso fictício para que o discente pudesse entrar em contato com a realidade.

Esta demonstração foi de suma importância, pois os estudantes puderam dirimir suas dúvidas em tempo real e perceberam a forma de abordagem do paciente a ser examinado. Ademais, os discentes realizaram o exame físico em suas respectivas duplas, podendo assim, vivenciar suas reais dificuldades ao se deparar com o ato de examinar. 
É imprescindivel que haja integração entre teoria e prática entre o pensar e o fazer, para que os discentes tornem-se independentes em sua prática. O conceito de "aprender fazendo" é essencial na formação na área da saúde, na qual há de se pensar na ideia de que o processo de ensinoaprendizagem necessita estar vinculado aos cenários da prática ${ }^{(12)}$.

No terceiro e último momento foi realizado um jogo educativo, no qual havia perguntas referentes ao conteúdo desenvolvido durante o curso. Nesta atividade foram feitos vários questionamentos a fim de despertar a reflexão dos discentes, comotambémavaliara aquisição deconhecimentos. O aspecto lúdico desse recurso metodológico, um jogo com imagens e cores, é capaz de estimular a interação entre os participantes e incita prazer por promover uma aprendizagem que desperta interesse de todos ${ }^{(13)}$.

$$
\text { O jogo desenvolvi- }
$$

do era constituído de um tabuleiro, envelopes contendo questões, um dado gigante e placas coloridas para identificação dos representantes dos grupos. O jogo foi confeccionado por meio de materiais acessiveis e de baixo custo. A representação do tabuleiro ocorreu por meio de quadrados construídos de material emborrachado dispostos no chão, os quais trilhavam um caminho a ser percorrido pelos discentes. Em cada quadrado, o participante que representava um grupo deveria responder a uma pergunta para que pudesse, em caso de acerto, percorrer o caminho trilhado pelo tabuleiro. O dado servia para dar direcionamento ao jogo, sendo feito de isopor e material emborrachado.

Os discentes agruparam-se em quatro equipes, sendo escolhido um componente para representar o grupo no tabuleiro. Em cada quadrado do tabuleiro o jogador representante deveria responder a uma pergunta, cuja resposta seria elaborada mediante discussão entre os constituintes do grupo durante tempo pré-estabelecido nas regras do jogo. Para cada resposta correta, o participante percorria a quantidade de casas de acordo coma complexidade da pergunta, de modo que, ao acertar uma pergunta fácil o representante andava um quadrado, intermediária dois quadrados, e difícil, três quadrados. Além disso, ao longo do tabuleiro estavam presentes quadrados com os seguintes enunciados "volte dois quadrados", "prisão", “avance um quadrado" e "escolha um participante para voltar dois quadrados". Ganhou o jogo o participante que chegou primeiro ao final do percurso e respondeu corretamente a "pergunta da vitória". Aos vencedores foram distribuidas premiações, obtidas por meio de doação, tais como estetoscópios e livros de enfermagem.

Sabe-se que os jogos educativos têm sido bastante difundidos como ferramenta de apoio pedagógico e considerados importantes estratégias de ensino, pois apresentam grande capacidade de incitar o interesse dos alunos pelos conteúdos ministrados em sala de aula, geram debates, fornecem informações e esclarecem dúvidas de forma satisfatória e dinâmica ${ }^{(13)}$. Tal técnica de ensino considera o conceito de lazer referido na literatura, no sentido de ser portador de um duplo aspecto educativo, veículo e objeto de educação, considerando-se assim, não apenas suas possibilidades de descanso e divertimento, mas também de desenvolvimento pessoal, social e inteletcual (14).

Durante a execução desta atividade, os discentes participaram ativamente, respondendo as perguntas baseadas nos conteúdos ministrados ao longo da disciplina e no curso de extensão. Foi uma forma interativa e divertida em que estes puderam expor seus conhecimentos sobre o assunto, e os docentes e monitores puderam realizar uma avaliação formativa acerca do conteúdo. É por meio da avaliação que o docente monitoriza o progresso do aluno, corrige suas falhas, dirime suas dificuldades, orienta e estimula os alunos ${ }^{(15)}$.

\section{CONSIDERAÇÕES FINAIS}

Diante da relevância da realização do exame físico para uma assistência de enfermagem sistematizada e da problemática que envolve o ensino do exame físico na graduação, concluise que os professores devem utilizar métodos e técnicas de ensino que possibilitem interações cada vez mais dinâmicas, em detrimento das tradicionais metodologias conservadoras que são, em essência, fragmentadas e reducionistas.

O discente, sujeito ativo e autônomo na construção do conhecimento, deverá ser capaz de perceber a importância do saber fazer no exame físico para que possa compreender 
a relevância dessa prática no contexto de sua atuação profissional, e assim, possa exercitar a liberdade e a autonomia na tomada de decisões, e consequentemente, tornar-se apto a prestar uma assistência de enfermagem de qualidade, eficiente, resolutiva e embasada cientificamente.
Portanto, odocente, no papel defacilitador, devecomprometerse com as práticas pedagógicas que sejam capazes de garantir a aquisição de um corpo de conhecimento significativo aos discentes que thes servirão de base durante toda sua vida profissional, garantindo assim a integralidade da atenção à saúde.

\section{REFERÊNCIAS}

1. Smeltzer SC, Bare BG. Hinkle JL, Cheever KH. Brunner \& Suddarth: Tratado de enfermagem médico-cirúrgica. 11ª ed. Rio de Janeiro: Guanabara Koogan; 2009.

2. Potter PA, Perry AG. Fundamentos de enfermagem. $7 \underline{a}$ ed. Rio de Janeiro: Elsevier; 2009

3. Barros ALB, Glashan RQ, Michel JLM. Bases propedêuticas para a prática de enfermagem: uma necessidade atual. Acta Paul Enf. [Internet]. 1996 [citado 2012 abr 04]; 9(1): 28-37. Disponivel em: http:// bases.bireme.br/cgibin/wxislind.exe/iah/online/?IsisScript=iah/iah. xis\&src=google\&base=LILACS\&lang=p\&nextAction=Ink\&exprSearch=2699638indexSearch=ID.

4. Sousa VD, Barros ALB. O ensino do exame fisico em escolas de graduação em enfermagem do municipio de São Paulo. Rev.latino -am.enfermagem. [Internet]. 1998 [citado 2012 abr 04]; 6(3): 11-22. Disponivel em: http://bases.bireme.br/cgi-bin/wxislind.exe/iah/online/?IsisScript=iah/iah.xis\&src=google\&base=LILACS\&lang=p\&nextAction=InkEexprSearch=229333\&indexSearch=ID.

5. Garcia TR, Nóbrega MML, Carvalho EC. Processo de enfermagem: aplicação à prática profissional. Online Braz. J. Nurs. [Internet]. 2004 [citado 2012 abr 04]; 3(2). Disponivel em: http://bases.bireme.br/cgibin/wxislind.exe/iah/online/?IsisScript=iah/iah.xis\&src=google\&base=LILACS\&lang=p\&nextAction=Ink\&exprSearch=490343\&indexSearch=ID.

6. Oliveira GF, Araújo CRD. Discentes de semiologia e semiotécnica em enfermagem II: análise da satisfação quanto à disciplina e à escolha da profissão. In: $X$ encontro de iniciação à docência. João Pessoa: Universidade Federal da Paraiba; 2012.

7. Conselho Federal de Enfermagem. Resolução COFEN no 358, de 15 de outubro de 2009: dispõe sobre a Sistematização da Assistência de Enfermagem e a implementação do Processo de Enfermagem em ambientes, públicos ou privados, em que ocorre o cuidado profissional de Enfermagem, e dá outras providências. Brasilia (DF); 2009.
8. Kolb D. Experimental learning. Englewood Cliffs (NJ): Prentice -Hall; 1984

9. Belnosky AM, Dziedzic MO. Ciclo de aprendizagem na prática de sala de aula. Athena Revista Científica de Educação. 2007; 8(8): 4353.

10. Barros ALBL, colaboradores. Anamnese e exame fisico [DVD]. Departamento de enfermagem da Universidade Federal de São Paulo; 2000.

11. Volpe RM, Sabbatini RME. Aplicações da multimidia no ensino médico. Revista Informédica. [Internet]. 1994 [citado 2012 jun 24]; 2(9): 5-12. Disponivel em: http://www.informaticamedica.org.br/informed/multimed.htm.

12. Mitre SM, Batista RS, Medonça JMG, Morais-Pinto NM, Meirelles CAB, Porto CP et al. Metodologias ativas de ensino -aprendizagem na formação profissional em saúde: debates atuais. Ciência e Saúde coletiva [Internet]. 2008 [citado 2012 jun 24]; 13(2): 2133-144. Disponivel em: http://www.scielosp.org/pdf/csc/v13s2/v13s2al8.pdf.

13. Rebello S, Monteiro S, Vargas EP. A visão de escolares sobre drogas no uso de um jogo educativo. Interface Com. Saude Educ [Internet]. 2001[citado 2012 jun 24]; 5 (8): 7588. Disponivel em: http://www.scielo.br/pdf/icse/v5n8/06. pdf.

14. Marcellino NC. Lazer e Qualidade de Vida. In: Moreira WN, organizador. Qualidade de Vida: Complexidade e educação. São Paulo: Papirus.

15. Santos MC, Leite MCL. A avaliação das aprendizagens na prática da simulação em enfermagem como feedback no ensino. Rev Gaúcha Enferm. [Internet]. 2010 [citado 2012 jul 15]: 31(3): 552-6. Disponivel em: http://seer.ufrgs. br/RevistaGauchadeEnfermagem/article/view/13434. 